\title{
Effects of Nori- and Wakame-enriched meats with or without supplementary cholesterol on arylesterase activity, lipaemia and lipoproteinaemia in growing Wistar rats
}

\author{
Raúl Olivero-David ${ }^{1,2}$, Adriana Schultz-Moreira ${ }^{2}$, Miguel Vázquez-Velasco ${ }^{2}$, Laura González-Torres ${ }^{2}$, \\ Sara Bastida ${ }^{2}$, Juana Benedī ${ }^{3}$, María Isabel Sanchez-Reus ${ }^{4}$, María José González-Muñoz ${ }^{1}$ \\ and Francisco J. Sánchez-Muniz ${ }^{2 *}$ \\ ${ }^{1}$ Departamento de Nutrición, Bromatología y Toxicología, Facultad de Farmacia, Universidad de Alcalá, Alcalá de Henares, \\ E-28871 Madrid, Spain \\ ${ }^{2}$ Departamento de Nutrición y Bromatología I (Nutrición), Facultad de Farmacia, Universidad Complutense de Madrid, \\ Plaza Ramón y Cajal s/n, E-28040 Madrid, Spain \\ ${ }^{3}$ Departamento de Farmacología, Facultad de Farmacia, Universidad Complutense de Madrid, E-28040 Madrid, Spain \\ ${ }^{4}$ Departamento de Bioquímica, Facultad de Farmacia, Universidad Complutense de Madrid, E-28040 Madrid, Spain
}

(Received 29 October 2010 - Revised 14 March 2011 - Accepted 17 March 2011 - First published online 3 June 2011)

\begin{abstract}
Some seaweeds exert antioxidant and hypocholesterolaemic properties. The effects of diets including restructured meats (RM) containing Wakame (W) or Nori (N) algae on arylesterase (AE) activity and lipoprotein concentration and composition were tested. In the present study, six groups of ten male growing Wistar rats each were fed a mix of $85 \%$ AIN-93M diet and $15 \%$ freeze-dried RM for $35 \mathrm{~d}$. The control group (C) consumed control RM, the W and N groups consumed RM with 5\% W and $5 \% \mathrm{~N}$, respectively. The cholesterol-enriched C (CC), $\mathrm{W}(\mathrm{CW})$ and $\mathrm{N}(\mathrm{CN})$ groups consumed their corresponding basal diets with supplementary cholesterol (2.43\%) and cholic acid (0.49\%). Cholesterol in the diet induced lower $(P<0.001)$ growth ratios. Both $\mathrm{W}$ and $\mathrm{N}$ diets significantly increased AE activity. VLDL-cholesterol values were lower in $\mathrm{N}$ rats than in W rats. AE activity increased $(P<0 \cdot 001)$ in $\mathrm{CC}$ and $\mathrm{CW}$ rats but not in $\mathrm{CN}$ rats compared with their corresponding counterparts. AE was lower $(P<0.05)$ in the $\mathrm{CN}$ group than in the CC and CW groups. The CN diet partially blocked $(P<0 \cdot 001)$ the hypercholesterolaemic induction observed in CC and CW diets and reduced TAG levels (at least $P<0 \cdot 05$ ) with respect to those of CC rats. Although dietary cholesterol supplementation increased total cholesterol, VLDL-cholesterol and (intermediate-density lipoprotein + LDL)cholesterol (all $P<0.001$ ) in all rats, the $\mathrm{CN}$ diet moderately improved the lipoprotein profile of hypercholesterolaemic rats. Changes in $\mathrm{AE}$ activity and plasma cholesterol in $\mathrm{CN}$ rats but not in $\mathrm{CW}$ rats suggest a possible relationship between the two parameters. It is concluded that inclusion of RM enriched with $\mathrm{N}$ may be used in hypercholesterolaemic diets to improve lipoprotein metabolism.
\end{abstract}

Key words: Nori: Wakame: Functional meats: Dietary cholesterol: Arylesterase: Lipids: Lipoproteins

Meat and meat products, which concentrate and supply a large number of valuable nutrients (proteins, fats, vitamins and minerals), have traditionally been basic components of the human diet. However, epidemiological associations between consumption of meat and meat derivatives and some of the major degenerative diseases such as CHD, cancer, high blood pressure and obesity have influenced nutritional thinking and dietary guidelines over the last few years $^{(1)}$. At present, the meat industry is introducing qualitative and/or quantitative modifications in meat and meat derivatives to create functional products ${ }^{(1,2)}$
Functional foods can be obtained by combining products such as meat products with physiologically active substances (e.g. from plants). Marine algae, traditional components of the Asian diet whose consumption in the Western world has increased considerably over the last decade, are known to contain such substances ${ }^{(3)}$. Some species of Undaria and Porphyra contain high levels of fibre, several minerals and vitamins, and their lipid content is normally $<1.0 \%$. Furthermore, it has been reported that these algae contain several minor compounds with beneficial biological $\operatorname{activities}^{(4)}$.

Abbreviations: AE, arylesterase; C, control; CC, cholesterol-enriched control; CN, cholesterol-enriched Nori; CW, cholesterol-enriched Wakame; IDL, intermediate-density lipoprotein; N, Nori; RM, restructured meat; W, Wakame.

* Corresponding author: Professor F. J. Sánchez-Muniz, fax +34 91 3941810, email frasan@farm.ucm.es 
Hypercholesterolaemia is associated with increased oxidative stress in animals ${ }^{(5)}$ and humans ${ }^{(6)}$. Increased dietary intake of antioxidants may thus reduce the incidence and prevalence of CHD and other degenerative diseases ${ }^{(7)}$. Our group has tested the effects of diets containing supplements of Nori (N) and $\mathrm{Konbu}^{(8)}$ and those of N- and Wakame (W)-enriched meat products ${ }^{(9)}$ on the antioxidant status of Wistar rats consuming high levels of cholesterol. It is well known that certain modifications of the lipoprotein profile increase the risk of developing atherosclerosis ${ }^{(10-13)}$. Moreover, increased lipoprotein oxidation constitutes one of the major emerging risk factors for atherosclerosis ${ }^{(14)}$. Arylesterase (AE), one of the enzymatic activities of paraoxonase- $1^{(15)}$, is known to play a protective role against peroxidation of LDL and other lipoproteins ${ }^{(15-18)}$. However, the effect on the lipoprotein profile of diets containing a high percentage of meat and seaweeds, with or without supplementary cholesterol, has not been studied previously. The inclusion of alga in restructured meat (RM) could have a double-edged effect, as both meat and seaweeds are rich in Fe and high levels of this metal are known to increase oxidative stress ${ }^{(19)}$. Due to the growing demand for alternative treatments for CHD, the present study aimed to investigate the effects of 5-week-long cholesterol-enriched and non-cholesterol-enriched diets that included restructured pork containing $\mathrm{W}$ or $\mathrm{N}$ on $\mathrm{AE}$ activity, lipaemia and lipoproteinaemia in growing Wistar rats.

In the present study, we hypothesise that certain seaweeds added to meat derivatives reduce the hypercholesterolaemic effect of cholesterol-enriched diets, partially normalising the lipoprotein profile. Moreover, alga-enriched meat increases AE activity, helping to maintain the antioxidant status of lipoproteins in rats fed diets that contain hypercholesterolaemic inductors.

\section{Materials and methods}

\section{Restructured meat preparation}

Meat raw materials (post-rigor pork and pork back fat), $\mathrm{W}$ (Undaria pinnatifida) and N (Porphyra umbilicalis) algae, and additives ( $\mathrm{NaCl}$, sodium tripolyphosphate and sodium nitrite) were used. Fresh marine seaweeds were collected on the Atlantic coast, dried in the shade and packed in polyethylene plastic bags for commercial distribution (Algamar C.B., Redondela, Pontevedra, Spain). These seaweeds were milled (Ultra Centrifugal Mill ZM 200; Retsch GmbH and Company, KG, Haan, Germany), passed through a $0.25 \mathrm{~mm}$ mesh sieve and stored in plastic flasks at $4 \pm 2{ }^{\circ} \mathrm{C}$ until used. Details of the RM preparation and composition have been published previously ${ }^{(2)}$. In brief, the raw meat was homogenised and ground for $1 \mathrm{~min}$ in a chilled cutter $\left(2^{\circ} \mathrm{C}\right.$; Stephan Universal Machine UM5; Stephan \& Sóhne $\mathrm{GmbH}$ and Company, Stephanplatz, Hameln, Germany). All the fat and half of the seaweeds, $\mathrm{NaCl}$ (2.0\% for control samples and $0.5 \%$ for samples with added seaweed), sodium tripolyphosphate and sodium nitrite were added to the ground meat and mixed together for $1 \mathrm{~min}$; the rest of the ingredients were then added, and the mixture was homogenised for $1 \mathrm{~min}$. The final mixture was homogenised under vacuum for $2 \mathrm{~min}$. Each sample was prepared in duplicate. RM-N and RM-W contained less Na than RM-C (385.5, 626.7 and $873.8 \mathrm{mg} / 100 \mathrm{~g} \mathrm{RM}$, respectively; Table 1). As reported by López-López et al. ${ }^{(2)}$, additional salt is required in the formulations without seaweed in order to overcome certain technological problems associated with low-salt products but was not necessary in the RM with algae ${ }^{(2)}$.

\section{Diet preparation and experimental design}

A total of sixty male growing Wistar rats with a body weight of approximately $90 \mathrm{~g}$ at the outset were obtained from Harlan Laboratories Models (Harlan, SL, Barcelona, Spain). The animals were housed individually in metabolic cells in a temperature-controlled room $\left(22 \cdot 3 \pm 1 \cdot 8^{\circ} \mathrm{C}\right)$ with a $12 \mathrm{~h}$ light $-12 \mathrm{~h}$ dark cycle. The present study was approved by the Spanish Science and Technology Advisory Committee (project AGL 2005-07 204-C02-01/ALI) and by an ethics committee of the Universidad Complutense of Madrid (Spain). All experiments were performed in compliance with Directive 86/609/EEC of 24 November 1986 for the protection of scientific research animals. The rats were fed commercial rat pellets (Panlab, Barcelona, Spain) during a 1-week period of adaptation to environmental conditions and then distributed into six groups of ten animals each, according to average body weight. The following six experimental semi-synthetic diets (Table 2) were prepared: (1) the control diet (C) without added cholesterol was composed of a homogeneous mixture

Table 1. Some relevant components of control, Wakame and Nori restructured meats*

\begin{tabular}{lccc}
\hline & Control & Wakame & Nori \\
\hline SFA (\% total fatty acids) & 36.72 & 38.49 & 35.82 \\
MUFA (\% total fatty acids) & 52.62 & 50.61 & 51.80 \\
PUFA (\% total fatty acids) & 10.66 & 10.91 & 12.38 \\
Polyphenols (gallic acid equivalents/100 g WM) & $\mathrm{Tr}$ & 820 & 2170 \\
Soluble fibre (g/100 g WM) & 0 & 1.1 & 1.33 \\
Insoluble fibre (g/100 g WM) & 2.81 & 1.2 & 0.66 \\
Total fibre (g/100 g WM) & 2.81 & 2.3 & 2.0 \\
Fe (mg/100 g WM) & 0.855 & 0.799 & 3.39 \\
Na (mg/100 g WM) & 872.8 & 626.7 & 385.5 \\
Lys:Met ratio & 2.95 & 2.95 & 3.16 \\
Antioxidant activity ( $\mu$ mol Trolox equivalents/g WM) & 0.77 & 1.09 & 1.18 \\
\hline
\end{tabular}

WM, wet matter.

* Data from López-López et al. ${ }^{(2)}$ 
Table 2. Composition $(\mathrm{g} / \mathrm{kg})$ and energy content $\dagger$ of the control, Wakame- and Nori-enriched meat diets with and without supplementary cholesterol*

\begin{tabular}{|c|c|c|c|c|}
\hline & \multicolumn{2}{|c|}{$\begin{array}{l}\text { Without supplementary } \\
\text { cholesterol }\end{array}$} & \multicolumn{2}{|c|}{$\begin{array}{l}\text { With supplementary } \\
\text { cholesterol }\end{array}$} \\
\hline & Control & Wakame or Nori & Control & Wakame or Nori \\
\hline \multicolumn{5}{|l|}{ Diet AIN-93M } \\
\hline Maize starch & $382 \cdot 75$ & 382.75 & 353.59 & 353.59 \\
\hline Cholesterol & & & 24.31 & 24.31 \\
\hline Cholic acid & & & 4.85 & 4.85 \\
\hline \multicolumn{5}{|l|}{ Pork (freeze-dried) $\ddagger$} \\
\hline Control meat $\ddagger$ & 150 & & 150 & \\
\hline Wakame-enriched meat $\ddagger$ or Nori-enriched meatł & & 150 & & 150 \\
\hline \multicolumn{5}{|c|}{$\begin{array}{l}\text { *Other ingredients: casein, } 127.5 \mathrm{~g} / \mathrm{kg} \text {; soyabean oil, } 34 \mathrm{~g} / \mathrm{kg} \text {; dyetrose (carbohydrate composition), } 131.75 \mathrm{~g} / \mathrm{kg} \text { (monosaccharides, } 10 \\
\text { g/kg; disaccharides, } 40 \mathrm{~g} / \mathrm{kg} \text {; trisaccharides, } 50 \mathrm{~g} / \mathrm{kg} \text {; tetrasaccharides and higher, } 900 \mathrm{~g} / \mathrm{kg} \text { ); sucrose, } 85 \mathrm{~g} / \mathrm{kg} ; \mathrm{microcrystalline} \mathrm{cellulose,} \\
42.50 \mathrm{~g} / \mathrm{kg} \text {; salt mix§, } 29.75 \mathrm{~g} / \mathrm{kg} \text {; vitamin mix\|, } 12.16 \mathrm{~g} / \mathrm{kg} \text {; choline bitartrate, } 3.06 \mathrm{~g} / \mathrm{kg} \text {; L-cystine, } 1.53 \mathrm{~g} / \mathrm{kg} ; t \text {-butylhydroquinone, } \\
0.0068 \mathrm{~g} / \mathrm{kg} \text {. }\end{array}$} \\
\hline \multicolumn{5}{|c|}{$\begin{array}{l}\text { † Diet energy content, considering as energy equivalent for monosaccharides; } 15.69 \mathrm{~kJ} / \mathrm{g}(3.75 \mathrm{kcal} / \mathrm{g}) ; \text { polysaccharides, } 16.73 \mathrm{~kJ} / \mathrm{g} \\
(4.0 \mathrm{kcal} / \mathrm{g}) ; \text { fat, } 37.65 \mathrm{~kJ} / \mathrm{g}(9.0 \mathrm{kcal} / \mathrm{g}) ; \text { protein } 16.73 \mathrm{~kJ} / \mathrm{g}(4.0 \mathrm{kcal} / \mathrm{g}) ; \text { soluble fibre, } 8.4 \mathrm{~kJ} / \mathrm{g}(2 \mathrm{kcal} / \mathrm{g}) ; \text { control diet without cholesterol, } \\
16587.7 \mathrm{~kJ} / \mathrm{kg}(3964.6 \mathrm{kcal} / \mathrm{kg}) ; \text { Wakame diet without added cholesterol, } 16790.9 \mathrm{~kJ} / \mathrm{kg}(4013.1 \mathrm{kcal} / \mathrm{kg}) ; \text { Nori diet without added choles- } \\
\text { terol, } 16677.9 \mathrm{~kJ} / \mathrm{kg}(3986.1 \mathrm{kcal} / \mathrm{kg}) ; \text { control diet with added cholesterol, } 16296.6 \mathrm{~kJ} / \mathrm{kg}(3895.0 \mathrm{kcal} / \mathrm{kg}) ; \text { Wakame diet with added } \\
\text { cholesterol, } 16106.0 \mathrm{~kJ} / \mathrm{kg}(3849.4 \mathrm{kcal} / \mathrm{kg}) ; \text { Nori diet with added cholesterol, } 16189.9 \mathrm{~kJ} / \mathrm{kg}(3869.5 \mathrm{kcal} / \mathrm{kg}) \text {. }\end{array}$} \\
\hline \multicolumn{5}{|c|}{$\begin{array}{l}\text { ¥Protein, fat, minerals (ash) and fibre present in the } 150 \mathrm{~g} \text { of control, Wakame and Nori freeze-dried, restructured meats; control meat: } \\
79.15,52.95,17.47 \text { and } 10 \mathrm{~g} \text { (microcrystalline cellulose), respectively; Nori meat: } 79.03,47.82,9.56 \text { and } 10.07 \mathrm{~g} \text {, respectively; Wakame } \\
\text { meat: } 73.75,52.98,17.14 \text { and } 11.95 \mathrm{~g} \text {, respectively. }\end{array}$} \\
\hline \multicolumn{5}{|c|}{ 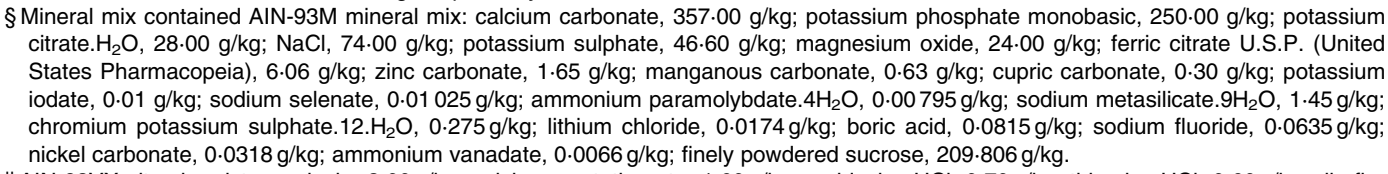 } \\
\hline \multicolumn{5}{|c|}{ 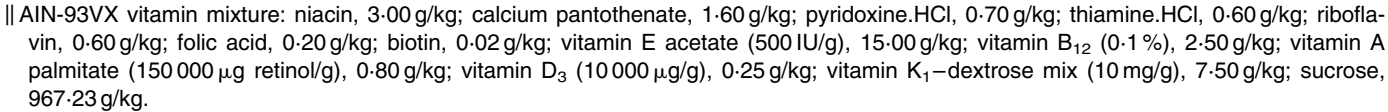 } \\
\hline
\end{tabular}

of $85 \%$ rodent diet (AIN-93M purified rodent diet; Dyets, Inc., Bethlehem, PA, USA) and 15\% freeze-dried restructured pork (with $4 \%$ wet matter microcrystalline cellulose); (2) the W diet consisted of a mixture of AIN-93M no. 180729 feed (85\%) and freeze-dried, restructured W meat (15\%); (3) the N diet consisted of a mixture of AIN-93M no. 180729 feed (85\%) and freeze-dried, restructured $\mathrm{N}$ meat (15\%); (4) the cholesterolenriched control (CC) diet was identical to the $\mathrm{C}$ diet but with $2 \cdot 43 \%$ cholesterol (95-98\% purity) and 0.49\% cholic acid ( $>98 \%$ purity), substituting an equal amount of starch (AIN-93M no. 180730 diet); (5) the cholesterol-enriched W (CW) diet was the $\mathrm{W}$ diet enriched with cholesterol and cholic acid; (6) the cholesterol-enriched N (CN) diet consisted of the $\mathrm{N}$ diet enriched with cholesterol and cholic acid. All experimental diets contained approximately $20.7 \%$ protein, $8.7 \%$ fat and $4.4 \%$ total dietary fibre. Water and food were provided ad libitum over the 5-week experimental period.

At the end of the experiment, in order to avoid inter-assay variations that could affect the comparison of data from the different groups, animals in fasting conditions were anaesthetised and euthanised by extracting blood from the descending aorta with a syringe, taking one animal at a time, of each one of six groups.

\section{Growth rate}

The feed conversion ratio was individually tested relating food consumption (g) to body-weight gain $(\mathrm{g})$.

\section{Lipoprotein isolation}

Blood from the descending aorta was collected into heparinised tubes. Plasma was separated from the whole blood within $30 \mathrm{~min}$ of collection by centrifugation at $2500 \mathrm{rpm}$ ( $1500 \mathrm{~g}$ ) for $20 \mathrm{~min}$ and kept at $4{ }^{\circ} \mathrm{C}$ until lipoprotein isolation. A SW 50.1 rotor was used to separate the various classes of lipoproteins in $1 \mathrm{ml}$ plasma samples. $\mathrm{KBr}\left(114 \times 10^{-3} \mathrm{~g}\right)$, sucrose $\left(25 \times 10^{-3} \mathrm{~g}\right)$ and serum $(1 \mathrm{ml})$ were added to the cellulose nitrate tube. The components were carefully mixed (final background density of $d=1 \cdot 10 \mathrm{~g} / \mathrm{ml}$ ) and sequentially overlaid with $2.4 \mathrm{ml}$ of a salt solution of $d=1.06 \mathrm{~g} / \mathrm{ml}$ $\left(11.42 \times 10^{-3} \mathrm{~g} \mathrm{NaCl}\right.$ and $\left.75.98 \times 10^{-3} \mathrm{~g} \mathrm{KBr} / \mathrm{ml}\right)$ and $2.4 \mathrm{ml}$ distilled water. After preparation, the gradients were spun for $7 \mathrm{~h}$ at $50000 \mathrm{rpm}(232000 \mathbf{g})$ and $4^{\circ} \mathrm{C}$, as indicated by Terpstra et $a l .{ }^{(20)}$.

Isolation of the lipoprotein fractions was performed taking into account the conventional boundaries for rats of the different lipoprotein classes ${ }^{(4)}$ (VLDL, $\rho_{20}<1.0063 \mathrm{~g} / \mathrm{ml}$; intermediatedensity lipoprotein (IDL) + LDL, $\rho_{20}=1 \cdot 0063-1.057 \mathrm{~g} / \mathrm{ml}$; HDL, $\left.\rho_{20}>1.057 \mathrm{~g} / \mathrm{ml}\right)$.

\section{Determination of cholesterol, phospholipids and TAG in the lipoprotein fractions}

Cholesterol, TAG and phospholipids were determined using standard enzymatic colorimetric tests (SpINREACT S.A., Sant Esteve de Bas, Girona, Spain). All intra-assay and inter-assay 
CV were $<5.5 \%$. Total lipids were calculated as the sum of cholesterol, TAG and phospholipids.

\section{Arylesterase activity measurement}

Rat plasma AE activity was measured according to Nus et $a l^{(16,17)}$. One unit of arylesterase was defined as the mmol phenol formed from phenyl acetate per min. Reaction rates were monitored at $270 \mathrm{~nm}$ in thermostated quartz cuvettes with a $10 \mathrm{~mm}$ light path, using a Shimadzu UV-2401 PC (Tokyo, Japan) spectrophotometer. Blanks without plasma samples were used to correct for the spontaneous hydrolysis of phenylacetate in the buffer. Each measurement was performed in duplicate.

\section{Statistical analyses}

Statistical analyses were performed using the SPSS version 15.0 statistical analysis package (SPSS, Inc., Chicago, IL, USA). The results are expressed as means and standard deviations or means with their standard errors. A two-way ANOVA (cholesterol and alga) was used. Pairwise comparisons of diet responses between groups were made employing the Bonferroni test. The effect of cholesterol consumption was evaluated using an unpaired Student's $t$ test. The relationship between food intake and body-weight gain, and the decrease in plasma cholesterol and the decrease in $\mathrm{AE}$ were tested by
Pearson's correlation test. Differences in growth rate induced by diets were assessed by the ANCOVA test. Differences were accepted as significant when $P<0.05$.

\section{Results}

\section{Restructured meat composition}

Table 1 shows some main differences between the RM compounds. RM-N contains higher soluble fibre, polyphenols and $\mathrm{Fe}$ than RM-W and RM-C. Minor differences were found in SFA, MUFA and PUFA percentages and in the lysine: methionine ratio. Diets have similar energy contents (16587.7$16677 \cdot 9 \mathrm{~kJ} / \mathrm{kg}(3964 \cdot 6-4013 \cdot 1 \mathrm{kcal} / \mathrm{kg})$ for non-added cholesterol diets and $16106 \cdot 0-16296 \cdot 6 \mathrm{~kJ} / \mathrm{kg}(3849 \cdot 4-3895 \cdot 0 \mathrm{kcal} / \mathrm{kg})$ for added cholesterol diets; Table 2).

\section{Growth rate}

Fig. 1(a)-(c) shows the relationship between food intake and body-weight gain and the intercepts, slopes and significances found for the different groups. There were no significant differences $(P>0.05)$ between the $\mathrm{N}$ and $\mathrm{W}$ diets, but the $\mathrm{N}$ diet induced a lower slope in body-weight evolution than the $\mathrm{C}$ diet $(P<0 \cdot 05)$. Supplementary dietary cholesterol significantly affected all growth curves (CC $v$. C; CW $v$. W and CN $v$. $\mathrm{N}$, all $P<0.001)$, but no significant differences $(P>0.05)$ between the $\mathrm{CN}$ and $\mathrm{CW}$ diets were found.
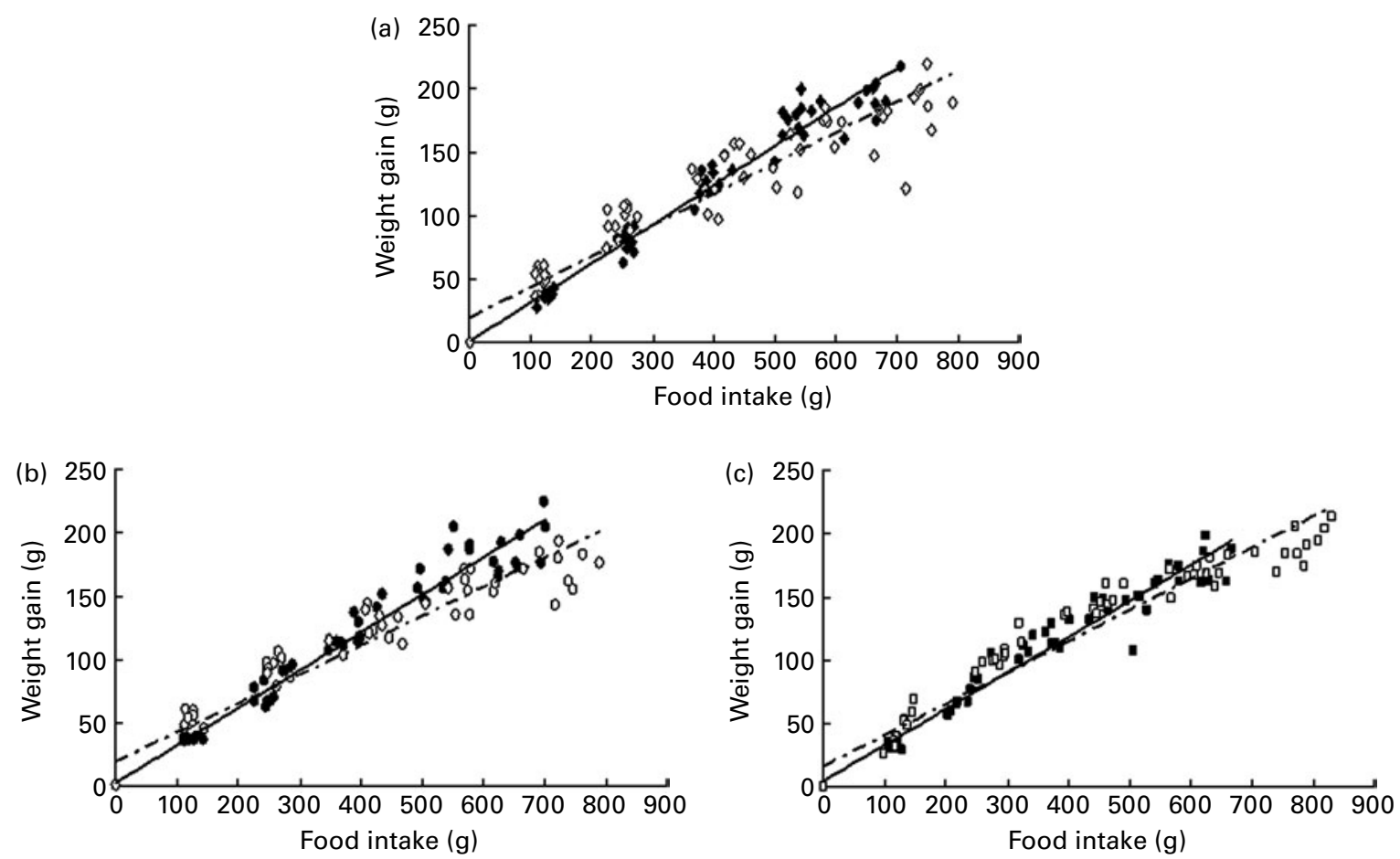

Fig. 1. Growth rates in rats fed the control, Wakame- and Nori-enriched meat experimental diets with and without supplementary cholesterol. $Y=$ (intercept with their standard error) + (slope with their standard error) $\times X$, where $Y$ is the body-weight gain and $X$ is the food consumption. (a) $\bullet$, control (C): $Y=(1.042 \pm 2.496)+(0.307 \pm 0.006) \times X ; r^{2} 0.9762 ; \diamond$, control with supplementary cholesterol $(\mathrm{CC}): Y=(19.44 \pm 4.21)+(0.243 \pm 0.010) \times X ; r^{2} 0.9039 .(b) \bullet$ Wakame $(\mathrm{W}): Y=(2.20 \pm 2.68)+(0.296 \pm 0.007) \times X ; r^{2} 0.9709 ; O$, Wakame with supplementary cholesterol $(\mathrm{CW}): Y=(19.10 \pm 3.66)+(0.229 \pm 0.009) \times X ;$ $r^{2}$ 0.9245. (c) $\square$, Nori (N) $Y=(4.86 \pm 2.84)+(0.283 \pm 0.007) \times X ; r^{2} 0.9667 ; \square$, Nori with supplementary cholesterol $(\mathrm{CN}): Y=(16.30 \pm 3.62)+(0.246 \pm 0.008) \times X$; $r^{2}$ 0.9448. Mean values were significantly different (ANCOVA test) for $\mathrm{C} v$. N $(P<0.05)$. Mean growth rate values were significantly different (ANCOVA test) for CC $v$. C, $\mathrm{CW} v$. W and $\mathrm{CN} v . \mathrm{N}(P<0.001)$. Mean growth rate values were not significantly different (ANCOVA test) for $\mathrm{C} v$. W, N v. W, CC v. CW, CW v. CN and CC v. CN. 
Table 3. Plasma cholesterol, TAG, phospholipids, total lipid, arylesterase (AE), and cholesterol:phospholipid, AE:total cholesterol and AE:HDL-cholesterol ratios in rats fed the control, Wakame- and Nori-enriched meat diets with and without the cholesterol supplement

(Mean values and standard deviations, $n 10$ )

\begin{tabular}{|c|c|c|c|c|c|c|c|c|c|c|}
\hline & \multirow{2}{*}{$\begin{array}{l}\text { Supplementary } \\
\text { cholesterol }\end{array}$} & \multicolumn{2}{|c|}{$\begin{array}{l}\text { Control groups } \\
(\mathrm{C} \text { and } \mathrm{CC})\end{array}$} & \multicolumn{2}{|c|}{$\begin{array}{l}\text { Wakame groups } \\
\text { (W and CW) }\end{array}$} & \multicolumn{2}{|c|}{$\begin{array}{l}\text { Nori groups } \\
(\mathrm{N} \text { and } \mathrm{CN})\end{array}$} & \multicolumn{3}{|c|}{ ANOVA } \\
\hline & & Mean & SD & Mean & SD & Mean & SD & Cholesterol effect & Diet effect & Interactio \\
\hline \multirow[t]{2}{*}{ Total cholesterol (mg/l) } & No & 596 & 164 & 544 & 89 & 526 & 115 & $<0.001$ & $<0.01$ & $<0.01$ \\
\hline & Yes & $2369^{\mathrm{a}^{\star \star \star}}$ & 579 & $31957^{\mathrm{a}, \mathrm{b}^{\mathrm{b*}}}$ & 957 & $1140^{b^{* *}}$ & 543 & & & \\
\hline \multirow[t]{2}{*}{ TAG $(\mathrm{mgl} / \mathrm{l}) \dagger$} & No & 621 & 144 & 712 & 228 & 475 & 238 & $<0.001$ & $<0.05$ & NS \\
\hline & Yes & $280^{\mathrm{a}^{\star \star \star}}$ & 57 & $234^{\mathrm{a}, \mathrm{b}^{\star \star * *}}$ & 85 & $183^{b^{\star \star}}$ & 48 & & & \\
\hline \multirow[t]{2}{*}{ Phospholipids (mg/l)† } & No & 1044 & 201 & 942 & 191 & 890 & 250 & $<0.001$ & NS & NS \\
\hline & Yes & 827 & 118 & 762 & 218 & $664^{*}$ & 176 & & & \\
\hline \multirow[t]{2}{*}{ Total lipids (mg/l)†‡ } & No & 2261 & 469 & 2093 & 569 & 1794 & 603 & $<0.001$ & NS & NS \\
\hline & Yes & $3510^{* *}$ & 708 & 2932 & 1080 & 2144 & 215 & & & \\
\hline \multirow[t]{2}{*}{ Cholesterol:phospholipid } & No & 0.56 & 0.05 & 0.58 & 0.03 & 0.59 & 0.07 & $<0.001$ & NS & NS \\
\hline & Yes & $2 \cdot 75^{\star \star \star}$ & 0.44 & $2 \cdot 76^{\star *}$ & 1.46 & $1.77^{\star \star \star}$ & 0.36 & & & \\
\hline \multirow[t]{2}{*}{$\mathrm{AE}(\mathrm{U} / \mathrm{I}) \ddagger$} & No & $10 \cdot 4^{\mathrm{b}}$ & $2 \cdot 8$ & $34 \cdot 8^{\mathrm{a}}$ & $10 \cdot 4$ & $43 \cdot 7^{\mathrm{a}}$ & $11 \cdot 1$ & $<0.001$ & $<0.01$ & $<0.001$ \\
\hline & Yes & $74 \cdot 1^{\mathrm{b}^{* *}}$ & 37.9 & $94 \cdot 6^{\mathrm{b}^{\star \star \star}}$ & $10 \cdot 7$ & $27 \cdot 4^{\mathrm{a}}$ & $19 \cdot 9$ & & & \\
\hline \multirow[t]{2}{*}{ AE:total cholesterol (U/mg) } & No & $0.015^{\mathrm{b}}$ & 0.003 & $0.063^{\mathrm{a}}$ & 0.013 & $0.085^{\mathrm{a}}$ & 0.033 & $<0.05$ & $<0.001$ & $<0.001$ \\
\hline & Yes & $0.036^{\mathrm{a}, \mathrm{b}^{*}}$ & 0.022 & $0.052^{\mathrm{a}}$ & 0.015 & $0.022^{\mathrm{b}^{* *}}$ & 0.006 & & & \\
\hline \multirow[t]{2}{*}{ AE:HDL-cholesterol (U/mg) } & No & $0 \cdot 016^{\mathrm{b}}$ & 0.003 & $0.077^{a}$ & 0.019 & $0.091^{a}$ & 0.04 & $<0.001$ & $<0.001$ & $<0.001$ \\
\hline & Yes & $0 \cdot 19^{b^{\star *}}$ & 0.01 & $0.51^{a^{*}}$ & $0 \cdot 19$ & $0 \cdot 11^{\mathrm{b}}$ & 0.08 & & & \\
\hline
\end{tabular}

C, control; CC, cholesterol control; W, Wakame; CW, cholesterol-enriched Wakame; N, Nori; CN, cholesterol-enriched Nori.

a,b Mean values within a row with unlike superscript letters were significantly different $(P<0.05$, Bonferroni's test).

Mean values within a column for the same parameter were significantly different from their no supplementary cholesterol counterparts: ${ }^{\star} P<0.05,{ }^{* *} P<0.01$ and ${ }^{* \star *} P<0.001$.

TTo transform $\mathrm{mg} / \mathrm{l}$ to $\mathrm{mmol} / \mathrm{l}$ of cholesterol, TAG and phospholipids, divide data by 387,890 and 750 , respectively.

Cholesterol + TAG + phospholipids. One unit of AE was defind as the mmol phenol formed from phenyl acetate per min. 


\section{Plasma lipid concentrations and arylesterase activities}

Plasma lipid data for the different groups are shown in Table 3. Significant cholesterol $\times$ type of diet interaction $(P<0 \cdot 001)$ was observed for total cholesterol and AE activity and the AE:total cholesterol and AE:HDL-cholesterol ratios. There were no significant differences $(P>0.05)$ between the $\mathrm{N}$ and W diets for total cholesterol, TAG, phospholipids, total lipids, cholesterol:phospholipids ratio, AE, AE:cholesterol ratio and $\mathrm{AE}: \mathrm{HDL}$-cholesterol ratio.

The hypercholesterolaemic dietary agent significantly increased plasma cholesterol levels in CC $(P<0.001)$, CW and $\mathrm{CN}$ animals (both $P<0 \cdot 01$ ). However, $\mathrm{CN}$ rats showed significantly $(P<0.001)$ lower cholesterol levels than CC rats. Plasma TAG levels were significantly affected by dietary cholesterol $(P<0.001)$ and type of diet $(P<0.05)$, while only dietary cholesterol significantly influenced phospholipids, total lipids and the cholesterol:phospholipid ratio (all $P<0.001)$. CN rats presented lower $(P<0.05)$ phospholipid concentrations than $\mathrm{N}$ rats. $\mathrm{CC}$ rats had higher total lipid levels $(P<0 \cdot 01)$ than $\mathrm{C}$ animals. The cholesterol: phospholipid ratio was significantly higher in $\mathrm{CC}, \mathrm{CW}$ and $\mathrm{CN}$ animals than in their $\mathrm{C}, \mathrm{W}$ and $\mathrm{N}$ counterparts $(P<0.001, \quad<0.01$ and $<0.001$, respectively). For the total cholesterol, TAG, phospholipids, total lipids and the cholesterol:phospholipid ratio, no significant differences $(P>0.05)$ between $\mathrm{CN}$ and $\mathrm{CW}$ rats were found.

The hypercholesterolaemic dietary agent significantly increased plasma AE activity in CC $(P<0.01)$ and $\mathrm{CW}$ animals $(P<0.001)$ but not in $\mathrm{CN}$ animals $(P>0.05)$. The AE:total cholesterol ratio increased in CC $(P<0.05)$ and $\mathrm{CN}$ animals $(P<0 \cdot 01) \quad v . \mathrm{C}$ and $\mathrm{N}$ animals, respectively. The $\mathrm{N}$ and $\mathrm{W}$ groups presented higher AE activity, AE:total cholesterol ratio and $\mathrm{AE}$ :HDL-cholesterol ratio than the $\mathrm{C}$ group (at least $P<0.05$; Table 3 ). CW rats showed a significantly higher $(P<0.05)$ AE:HDL-cholesterol ratio than the $\mathrm{CN}$ and $\mathrm{CC}$ groups. $\mathrm{CN}$ rats showed a lower $(P<0.05)$ $\mathrm{AE}, \mathrm{AE}$ :total cholesterol ratio and AE:HDL-cholesterol ratio than $\mathrm{CW}$ rats.

\section{Lipoprotein profile}

The lipid content of the different lipoprotein fractions is shown in Table 4. A significant cholesterol $\times$ type of diet interaction was observed for VLDL-cholesterol and (IDL + LDL)-cholesterol (both $P<0.05$ ). Supplementary dietary cholesterol affected the cholesterol, TAG and phospholipid content of all the lipoproteins $(P<0.001)$ except VLDLphospholipids and HDL-cholesterol (both $P>0.05$ ). The type of diet affected VLDL-cholesterol and (IDL + LDL)cholesterol (both $P<0.05)$ and HDL-TAG $(P<0 \cdot 01)$. When results were studied according to the cholesterol supplement status of each group, $\mathrm{N}$ rats displayed lower VLDL-cholesterol levels than $\mathrm{W}$ rats $(P<0.05)$, while the $\mathrm{CN}$ group had lower VLDL-cholesterol and HDL-TAG concentrations than CC animals.

CC animals presented significantly higher levels of VLDLcholesterol $(P<0 \cdot 01), \quad(\mathrm{IDL}+\mathrm{LDL})$-cholesterol $\quad(P<0 \cdot 001)$ and (IDL + LDL)-phospholipids $(P<0 \cdot 001)$, and lower concentrations of VLDL-TAG $(P<0 \cdot 01)$, (IDL + LDL)-TAG $(P<0.05)$, HDL-TAG $(P<0.001)$ and HDL-phospholipids $(P<0 \cdot 001)$ than their $\mathrm{C}$ counterparts. Compared with $\mathrm{N}$ rats, $\mathrm{CN}$ animals had higher (IDL $+\mathrm{LDL})$-cholesterol $(P<0 \cdot 01)$ and (IDL + LDL)-phospholipid $(P<0.05)$ levels and lower HDL-cholesterol $(P<0 \cdot 05)$, VLDL $(P<0 \cdot 01)$, (IDL + LDL)TAG $(P<0.05)$ and HDL-phospholipid $(P<0.05)$ values. VLDL-cholesterol $(P<0 \cdot 05)$, (IDL + LDL)-cholesterol $(P<0 \cdot 001)$ and (IDL + LDL)-phospholipid $(P<0 \cdot 01)$ concentrations were higher in $\mathrm{W}$ rats than in $\mathrm{CW}$ rats, while VLDL-TAG $(P<0 \cdot 001)$, (IDL + LDL)-TAG $(P<0.05)$, HDL-TAG $(P<0.05)$ and HDLphospholipids $(P<0.001)$ were lower.

\section{Percentage contribution of lipids to lipoprotein composition}

Fig. 2(a)-(c) shows the percentage contribution of the different lipids (\% contribution) to the total VLDL, IDL + LDL and HDL lipid mass. A significant cholesterol $\times$ type of diet interaction was observed for the percentage of cholesterol in VLDL $(P<0 \cdot 05)$. Cholesterol supplementation influenced the cholesterol, TAG and phospholipid composition of VLDL (all $P<0.001$ ).

$\mathrm{CC}, \mathrm{CW}$ and $\mathrm{CN}$ rats presented VLDL and IDL + LDL particles enriched in cholesterol but impoverished in TAG (both $P<0.001$ ) with respect to VLDL and IDL + LDL of $\mathrm{C}$, $\mathrm{W}$ and $\mathrm{N}$ animals, respectively (Fig. 2(a) and (b)). CN rats had VLDL with less cholesterol $(P<0.05)$ than VLDL of CC and $\mathrm{CW}$ rats, and more TAG $(P<0.05)$ than VLDL of $\mathrm{CW}$ rats (Fig. 2(a)). HDL particles of $\mathrm{W}$ rats had less cholesterol and more TAG (both $P<0.05$ ) than HDL particles of $\mathrm{N}$ rats (Fig. 2(c)). HDL particles of $\mathrm{CC}, \mathrm{CW}$ and $\mathrm{CN}$ rats were impoverished in phospholipids with respect to HDL particles of $\mathrm{C}, \mathrm{W}$ and $\mathrm{N}$ animals, respectively $(P<0.01,<0.05$ and $<0 \cdot 05$, respectively) (Fig. 2(c)). HDL particles of CC animals were enriched in cholesterol $(P<0.01)$ with respect to HDL of the $\mathrm{C}$ group, while HDL particles of $\mathrm{CN}$ rats were enriched in TAG $(P<0 \cdot 01)$ with respect to HDL particles of $\mathrm{N}$ rats (Fig. 2(c)).

\section{Discussion}

The present study shows for the first time that how the consumption of seaweed-enriched meats, with or without cholesterol supplementation, influences rat plasma AE activity and the lipoprotein profile.

In the present study, diets containing seaweed-enriched RM were generally well accepted by growing rats, as corroborated by similar intake data from other studies ${ }^{(8,21,22)}$. Rats given the $\mathrm{N}$ diet consumed less feed than those of the control group, probably due to the high soluble fibre content of the $\mathrm{N}$ alga. In agreement with Beynen et $a l^{(23)}$, supplementary dietary cholesterol decreased the growing rate. Mahfouz \& Kummerow $^{(5)}$ found lower body-weight gain in rabbits but not in rats fed cholesterol-enriched diets. 
Table 4. Lipoprotein lipid concentration in rats fed the control, Wakame- and Nori-enriched meat diets with and without cholesterol supplement (Mean values and standard deviations)

\begin{tabular}{|c|c|c|c|c|c|c|c|c|c|c|}
\hline & \multirow{2}{*}{$\begin{array}{c}\text { Added } \\
\text { cholesterol }\end{array}$} & \multicolumn{2}{|c|}{$\begin{array}{l}\text { Control groups } \\
\text { (C and CC) }\end{array}$} & \multicolumn{2}{|c|}{$\begin{array}{l}\text { Wakame groups } \\
\text { (W and CW) }\end{array}$} & \multicolumn{2}{|c|}{$\begin{array}{l}\text { Nori groups } \\
\text { ( } \mathrm{N} \text { and } \mathrm{CN})\end{array}$} & \multicolumn{3}{|c|}{ ANOVA } \\
\hline & & Mean & SD & Mean & SD & Mean & SD & Cholesterol effect & Diet effect & Interaction \\
\hline \multicolumn{11}{|c|}{ Cholesterol $(\mathrm{mg} / \mathrm{l}) \dagger$} \\
\hline \multirow[t]{2}{*}{ VLDL } & No & $42 \cdot 3^{a, b}$ & 18.9 & $65 \cdot 2^{\mathrm{a}}$ & 32.9 & $28.4^{b}$ & 13.4 & $<0.001$ & $<0.05$ & $<0.05$ \\
\hline & Yes & $524 \cdot 4^{\mathrm{a}^{\star \star}}$ & 411.5 & $373 \cdot 1^{\mathrm{a}, \mathrm{b}^{*}}$ & 267.4 & $112 \cdot 3^{b}$ & $163 \cdot 4$ & & & \\
\hline \multirow[t]{2}{*}{ IDL + LDL } & No & 11.6 & $6 \cdot 0$ & $21 \cdot 3$ & $13 \cdot 1$ & 13.5 & $7 \cdot 4$ & $<0.001$ & $<0.05$ & $<0.05$ \\
\hline & Yes & $1251 \cdot 2^{\star \star \star}$ & $383 \cdot 8$ & $1165 \cdot 7^{\star \star *}$ & $498 \cdot 7$ & $690 \cdot 2^{\star *}$ & 386.9 & & & \\
\hline \multirow[t]{2}{*}{$\mathrm{HDL}$} & No & $535 \cdot 3$ & $142 \cdot 1$ & $442 \cdot 3$ & 48.9 & $495 \cdot 1$ & $112 \cdot 8$ & NS & NS & NS \\
\hline & Yes & 487.4 & $249 \cdot 7$ & $374 \cdot 1$ & $350 \cdot 2$ & $297 \cdot 5^{\star}$ & 152.9 & & & \\
\hline \multicolumn{11}{|l|}{ TAG $(\mathrm{mg} / \mathrm{l}) \dagger$} \\
\hline \multirow[t]{2}{*}{ VLDL } & No & 321.9 & $122 \cdot 5$ & $428 \cdot 6$ & 187.5 & $270 \cdot 0$ & $172 \cdot 6$ & $<0.001$ & NS & NS \\
\hline & Yes & $88 \cdot 3^{\star \star}$ & $48 \cdot 3$ & $56 \cdot 7^{\star \star \star}$ & 20.5 & $47 \cdot 3^{\star \star}$ & 43.7 & & & \\
\hline \multirow[t]{2}{*}{$\mathrm{IDL}+\mathrm{LDL}$} & No & $59 \cdot 2$ & $18 \cdot 4$ & $50 \cdot 2$ & $24 \cdot 3$ & 38.7 & $18 \cdot 7$ & $<0.001$ & NS & NS \\
\hline & Yes & $26 \cdot 3^{*}$ & $8 \cdot 7$ & $25 \cdot 1^{*}$ & $10 \cdot 0$ & $18 \cdot 9^{*}$ & $12 \cdot 9$ & & & \\
\hline \multirow[t]{2}{*}{$\mathrm{HDL}$} & No & 207.9 & $25 \cdot 8$ & $220 \cdot 3$ & $47 \cdot 6$ & $157 \cdot 9$ & $56 \cdot 6$ & $<0.001$ & $<0.01$ & NS \\
\hline & Yes & $168 \cdot 1^{\mathrm{a}^{\star \star \star}}$ & 28.5 & $154 \cdot 2^{\mathrm{a}, \mathrm{b}^{*}}$ & $53 \cdot 2$ & $120 \cdot 2^{b}$ & 14.5 & & & \\
\hline \multicolumn{11}{|c|}{ Phospholipids (mg/l)† } \\
\hline \multirow[t]{2}{*}{ VLDL } & No & $101 \cdot 5$ & $45 \cdot 7$ & $86 \cdot 2$ & 57.5 & $52 \cdot 2$ & 31.4 & $<0.05$ & NS & NS \\
\hline & Yes & $216 \cdot 6^{\star}$ & $134 \cdot 2$ & $199 \cdot 2$ & $230 \cdot 7$ & $64 \cdot 7$ & $79 \cdot 3$ & & & \\
\hline \multirow[t]{2}{*}{$\mathrm{IDL}+\mathrm{LDL}$} & No & $15 \cdot 4$ & 5.9 & $10 \cdot 1$ & 3.8 & $19 \cdot 0$ & 13.3 & $<0.001$ & NS & NS \\
\hline & Yes & $209 \cdot 5^{\star \star *}$ & $75 \cdot 9$ & $179 \cdot 8^{\star \star}$ & $82 \cdot 6$ & $146 \cdot 0^{\star}$ & 111.5 & & & \\
\hline \multirow[t]{2}{*}{$\mathrm{HDL}$} & No & $900 \cdot 2$ & $163 \cdot 9$ & 848.9 & $112 \cdot 1$ & $840 \cdot 3$ & $203 \cdot 3$ & $<0.001$ & NS & NS \\
\hline & Yes & $417 \cdot 7^{\star \star \star}$ & $126 \cdot 2$ & $345 \cdot 6^{* \star *}$ & $82 \cdot 2$ & $399 \cdot 7^{\star *}$ & 61.6 & & & \\
\hline \multicolumn{11}{|c|}{ Total lipids (mg/l)†‡ } \\
\hline \multirow[t]{2}{*}{ VLDL } & No & $465 \cdot 6$ & $163 \cdot 3$ & $602 \cdot 6$ & $271 \cdot 3$ & $360 \cdot 3$ & $221 \cdot 3$ & NS & $<0.05$ & NS \\
\hline & Yes & $829 \cdot 2$ & $567 \cdot 1$ & $629 \cdot 1$ & $469 \cdot 7$ & $224 \cdot 3$ & 283.4 & & & \\
\hline \multirow[t]{2}{*}{ IDL + LDL } & No & $86 \cdot 2$ & $21 \cdot 7$ & $80 \cdot 2$ & 29.9 & 69.4 & $25 \cdot 3$ & $<0.001$ & $<0.05$ & NS \\
\hline & Yes & $1486 \cdot 9^{\star \star \star}$ & 454.4 & $1370 \cdot 6^{\star \star \star}$ & $514 \cdot 3$ & $855 \cdot 1^{\star}$ & $497 \cdot 0$ & & & \\
\hline \multirow[t]{2}{*}{$\mathrm{HDL}$} & No & $1643 \cdot 4$ & 286.5 & $1509 \cdot 2$ & $180 \cdot 5$ & 1488.5 & $350 \cdot 3$ & $<0.001$ & NS & NS \\
\hline & Yes & $1073 \cdot 2^{*}$ & 3716 & $873 \cdot 8^{\star \star \star}$ & $360 \cdot 1$ & $817 \cdot 4^{\star \star \star}$ & $213 \cdot 7$ & & & \\
\hline
\end{tabular}

C, control; CC, cholesterol control; W, Wakame; CW, cholesterol-enriched Wakame; N, Nori; CN, cholesterol-enriched Nori; IDL, intermediate-density lipoprotein

$\mathrm{a,b}$ Mean values within a row with unlike superscript letters were significantly different $(P<0.05$, Bonferroni's test).

Mean values within a column for the same parameter were significantly different from their no supplementary cholesterol counterparts: ${ }^{*} P<0.05,{ }^{* \star} P<0.01$ and ${ }^{\star \star \star} P<0.001$.

†To transform $\mathrm{mg} / \mathrm{l}$ to $\mathrm{mmol} / \mathrm{l}$ of cholesterol, TAG and phospholipids, divide data by 387,890 and 750 , respectively.

‡Cholesterol + TAG + phospholipids. 

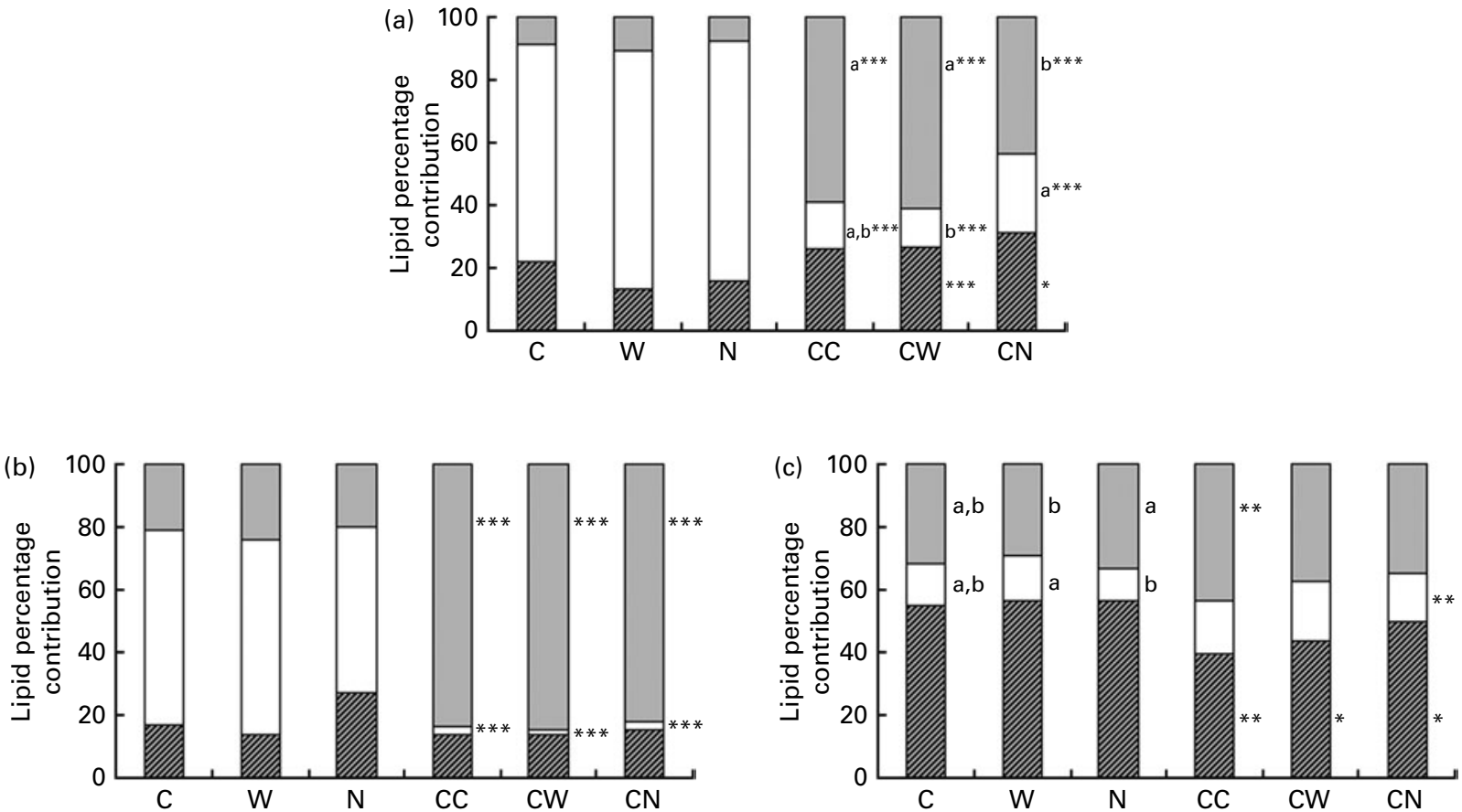

Fig. 2. Percentage contribution (\%) of the different lipids to the total lipid mass of (a) VLDL, (b) intermediate-density lipoprotein (IDL) + LDL and (c) HDL in rats fed the control (C), Wakame (W)- and Nori (N)-enriched meat experimental diets and the cholesterol-enriched control (CC), Wakame (CW) and Nori (CN) meat experimental diets. Mean values were significantly different for cholesterol $\times$ diet interaction for VLDL-cholesterol and LDL + IDL-TAG $(P<0 \cdot 05)$. ${ }^{\text {,b }}$ Mean values within the same lipoprotein lipid for $\mathrm{C}, \mathrm{W}$ and $\mathrm{N}$ or for $\mathrm{CC}, \mathrm{CW}$ and $\mathrm{CN}$ with unlike letters were significantly different $(P<0.05$, Bonferroni's test), represented by vertical bar areas. Mean values within the same lipoprotein for $\mathrm{C} v$. CC, $\mathrm{W} v$. CW and $\mathrm{N} v$. CN were significantly different (represented by vertical bar areas) $\left({ }^{\star} P<0.05,{ }^{\star *} P<0.01\right.$ and $\left.{ }^{\star \star *} P<0.001\right)$. $\square$, Cholesterol; $\square$, TAG; $\square$, phospholipids.

\section{Lipidaemia and lipoproteinaemia and plasma arylesterase activity}

Several animal models have been used to study cholesterol and atherogenesis, but no single model is considered perfect for extrapolating results to humans ${ }^{(24)}$. Rats are the animals most commonly used in cholesterol metabolism studies and one of the most often used to study the cholesterolaemic effect of proteins ${ }^{(24-27)}$. Bovine bile or colic acid has been extensively used in animal studies to increase dietary cholesterol absorption and thus the hypercholesterolaemic effect of this sterol ${ }^{(24-28)}$. Dietary casein does not induce hypercholesterolaemia when the diet contains no cholesterol supplement $^{(21)}$. The present study demonstrated that when cholesterol was not added to the diet, the consumption of $\mathrm{C}, \mathrm{W}$ and $\mathrm{N}$ maintained normal levels of cholesterol, TAG and phospholipids in rats ${ }^{(4,29-31)}$. In addition, the cholesterol: phospholipid ratio, used as a marker of hypercholesterolaemia ${ }^{(29)}$, remained low in $\mathrm{C}, \mathrm{W}$ and $\mathrm{N}$ rats, suggesting normocholesterolaemia $^{(29)}$. Inclusion of seaweed-enriched RM in the diet increased AE activity, suggesting an improvement in antioxidant status. AE, which binds to HDL and other lipoproteins ${ }^{(32)}$, is involved in lipoprotein metabolism and inhibits lipoperoxidation in LDL and $\mathrm{HDL}^{(33)}$. AE activity increases in rats consuming pomegranate polyphenols ${ }^{(34)}$ or seaweeds ${ }^{(4)}$. The presence of antioxidants and other phytochemicals in algae $^{(4)}$ at least partially explains the greater absolute $\mathrm{AE}$ activity in $\mathrm{N}$ and $\mathrm{W}$ rats than that observed in $\mathrm{C}$ animals.
The same effect or tendency was observed when data were adjusted for cholesterol and HDL-cholesterol.

The absolute lipid content and composition of IDL + LDL and HDL in the $\mathrm{C}$ group were comparable with those reported in other studies ${ }^{(13,35)}$. HDL-cholesterol accounts for $85 \%$ or more of total cholesterol. Rats, moreover, display a very effective uptake of VLDL and a low transference of apoB from VLDL to $\mathrm{LDL}^{(36)}$, which explain the low levels of LDL found in the present study and in previous investigations ${ }^{(13,29,35,37)}$.

In general terms, lipoprotein fraction composition was similar in $\mathrm{C}, \mathrm{W}$ and $\mathrm{N}$ rats. Nonetheless, the VLDL lipid mass (cholesterol + TAG + phospholipids) was higher in rats on the $\mathrm{W}$ diet and lower in those fed the $\mathrm{N}$ diet, suggesting that the former diet increased the production of lipoproteins while the latter decreased it. According to their lipid composition, the HDL of $\mathrm{N}$ rats appears to be more anti-atherosclerotic lipoproteins than the HDL of $\mathrm{W}$ rats $^{(37)}$. Differences in lipid and lipoprotein levels between groups without the cholesterol supplement must first be attributed to the different total fibre and soluble fibre contents of the diets and, second, to other compounds, such as minerals, which may also affect lipaemia ${ }^{(3,4,38)}$. N contains more viscous-soluble fibre and polyphenols than W, partially explaining why lipaemia values in $\mathrm{W}$ rats were higher than those in their $\mathrm{N}$ counterparts. A previous publication of our group ${ }^{(39)}$ has reported that algal remains were found in the caecum of rats fed Konbu seaweed, but not in animals fed N, suggesting clear differences in gastric emptying time and digestion speed between the two algal diets. 
Consistent with the results of other studies ${ }^{(25-27,40,41)}$, the CC diet induced hypercholesterolaemia and decreased triacylglycerolaemia $^{(4,21,37)}$, producing very large amounts of $\beta$-VLDL and large quantities of LDL, and reducing the amount of total lipids transported by the HDL fraction. The $\mathrm{CN}$ diet partially blocked the hypercholesterolaemic induction observed in the CC and CW diets. As commented earlier, the higher soluble fibre and polyphenols of $\mathrm{N}$ than $\mathrm{W}^{(2)}$ may be involved in the hypocholesterolaemic effect of the $\mathrm{CN}$ diet. These results were similar to those observed after adding $\mathrm{N}(7 \%)^{(4)}$ or fried sardines ${ }^{(26)}$ to cholesterol-enriched diets.

The hypercholesterolaemic treatment increased AE activity in CC and CW rats, but unexpectedly, this was not observed in rats consuming the $\mathrm{CN}$ diet. Some algal compounds could be involved. RM-N contains three times more Fe than RM-W or RM-C; thus, a higher pro-oxidant effect in the CN group than in the other groups could be expected in the framework of cholesterol-enriched diets. Cholesterol is mainly eliminated from the body via bile acid production. Biosynthesis of cholic acid via cytochrome $\mathrm{P} 450$ increases the production of free radical substances. Thus, AE activity could be used to avoid lipoprotein peroxidative damage ${ }^{(42,43)}$, acting as a suicide enzyme in $\mathrm{CN}$ animals ${ }^{(43)}$. In fact, a positive and significant correlation $(P=0.030)$ was found between the decrease in cholesterol and that in $\mathrm{AE}$ in the $\mathrm{CW}+\mathrm{CN}$ groups with respect to the CC group (data not shown).

These results differ from those found by Bocanegra et al. ${ }^{(4)}$, as $\mathrm{AE}$ decreased in non-fasted rats fed the cholesterolenriched control diet. However, similar data were obtained in rats fed the diet enriched in $\mathrm{N}$ and cholesterol. Thus, fasting and/or certain meat compounds, such as Fe, may explain differences between control diets of both studies. Nonetheless, the results on $\mathrm{AE}$ are difficult to be explained and deserve further studies to be confirmed.

TAG levels of $\mathrm{N}$ rats tended to be lower than those of $\mathrm{C}$ rats, while those of $\mathrm{W}$ animals were higher. Bocanegra et al. ${ }^{(4)}$ observed that postprandial TAG levels in control rats were similar to those given $\mathrm{N}$ for 3 weeks, while Murata et al. ${ }^{(44)}$ reported that plasma and liver cholesterol levels decreased in rats given a diet containing a mixture of fish and $\mathrm{W}$ for 4 weeks

Plasma cholesterol levels rose in all rats consuming cholesterol-enriched diets, but particularly in CC and CW rats due to an increase in cholesterol-enriched $\mathrm{VLDL}^{(4,23,25,37)}$. VLDLcholesterol concentrations of $\mathrm{CN}$ animals decreased, while those of $\mathrm{CW}$ rats resembled those of CC animals, suggesting that the $\mathrm{N}$ diet decreased $\beta$-VLDL levels, partially normalising the VLDL fraction of $\mathrm{CN}$ animals. Some researchers have reported that the water-soluble fractions of seaweeds or isolated algal polysaccharides showed hypocholesterolaemic and anti-hypertensive properties in experimental animals, a finding that would explain the hypocholesterolaemic effect of the $\mathrm{CN}$ diet in rats of the present study ${ }^{(13,45)}$.

The lipid content of the IDL + LDL fraction increased several-fold in animals given the cholesterol-enriched diets. However, this increase in $\mathrm{CN}$ rats was of lower magnitude than in $\mathrm{CC}$ or $\mathrm{CW}$ rats. Rats, moreover, display a very effective uptake of VLDL and a low transference of apoB from VLDL to
LDL $^{(46)}$. According to Havel ${ }^{(47)}$, large VLDL contributes less to the formation of LDL than small VLDL in rats and other animals.

HDL-cholesterol levels were lower in CC, CW and CN animals than in their $\mathrm{C}, \mathrm{W}$ and $\mathrm{N}$ counterparts. The hepatic scavenger receptor B-I plays an essential role in the hepatic uptake of plasma HDL-derived cholesterol and cholesterol esters for excretion into the bile ${ }^{(48-50)}$. Scavenger receptor B-I deficiency results in a significant increase in plasma HDL-cholesterol and increased atherosclerotic lesions in a mouse ${ }^{(51)}$. Combined deficiencies of scavenger receptor B-I and apoE profoundly alter lipoprotein metabolism, plasma cholesterol in VLDL-sized and in abnormally large HDL-like particles ${ }^{(51)}$. This may explain the lower HDL-cholesterol in rats given the cholesterol-enriched diets than in those on the non-cholesterol-enriched diets.

In conclusion, diets including seaweed-enriched meat were well accepted and resulted in acceptable growth ratios and increased AE activity. The present results suggest the convenience of including only some specific seaweeds in meat derivatives to obtain functional meats, as $\mathrm{N}$ but not $\mathrm{W}$ partially blocked the hypercholesterolaemic effect of dietary cholesterol and partially normalised VLDL and LDL lipid levels and composition. Future studies are needed to understand the relationship between $\mathrm{AE}$ and cholesterol changes. The convenience of studying the effect of seaweed-enriched RM on lipid metabolism in different models, including human subjects, is emphasised.

\section{Acknowledgements}

The present study was supported by the Spanish projects AGL2005-07204-C02-01/ALI, AGL-2008 04892-C03-02 and Consolider-Ingenio 2010 project no. CSD2007-00016. We gratefully acknowledge the predoctoral fellowship of the Fundación Gran Mariscal de Ayacucho (FUNDAYACUCHO) from the Bolivarian Republic of Venezuela to R. O.-D., that of the Universidad Complutense, Madrid, Spain to A. S.-M. and the foreign fellowship for graduate studies granted by the Consejo Nacional de Ciencia y Tecnología (CONACYT) of México to L. G.-T. All authors have significantly contributed to the manuscript and agree with the present version of the paper. F. J. S.-M. contributed to the study design, data discussion and writing of the manuscript. R. O.-D., A. S.-M., L. G.-T. and S. B. contributed to the data acquisition and analysis and writing of the manuscript. J. B., M. J. G.-M., M. V.-V. and M. I. S.-R. contributed to the data discussion and made a critical review of the manuscript. The authors declare that there are no conflicts of interest.

\section{References}

1. Jimenez-Colmenero F, Carballo J \& Cofrades S (2001) Healthier meat and meat products: their role as functional foods. Meat Sci 59, 5-13

2. López-López I, Bastida S, Ruiz-Capillas C, et al. (2009) Composition and antioxidant capacity of low-salt meat emulsion model systems containing edible seaweeds. Meat Sci $\mathbf{8 3}$, 492-498. 
3. Bocanegra A, Bastida S, Benedi J, et al. (2009) Characteristics and nutritional and cardiovascular-health properties of seaweeds. J Med Food 12, 1-24.

4. Bocanegra A, Bastida S, Benedi J, et al. (2009) Effect of seaweed and cholesterol-enriched diets on postprandial lipoproteinaemia in rats. Br J Nutr 102, 1728-1739.

5. Mahfouz MM \& Kummerow FA (2000) Cholesterol-rich diets have different effects on lipid peroxidation, cholesterol oxides and antioxidant enzymes in rats and rabbits. $J$ Nutr Biochem 11, 293-302.

6. Napoli C, Glass CK, Witztum JL, et al. (1999) Influence of maternal hypercholesterolaemia during pregnancy on progression of early atherosclerotic lesions in childhood: Fate of Early Lesions in Children (FELIC) study. Lancet 354, $1234-1241$.

7. Iwai K (2008) Antidiabetic and antioxidant effects of polyphenols in brown Alga Ecklonia stolonifera in genetically diabetic KK-A(y) mice. Plant Foods Hum Nutr 63, 163-169.

8. Bocanegra A, Benedi J \& Sanchez-Muniz FJ (2006) Differential effects of Konbu and Nori seaweed dietary supplementation on liver glutathione status in normo and hypercholesterolaemic growing rats. Br J Nutr 95, 696-702.

9. Schultz Moreira A, González-Torres L, Olivero-David R, et al. (2010) Wakame and Nori in restructured meats included in cholesterol-enriched diets affect the antioxidant enzyme gene expressions and activities in Wistar rats. Plant Foods Hum Nutr 65, 290-298.

10. Barter PJ \& Rye KA (1996) High density lipoproteins and coronary heart disease. Atherosclerosis 121, 1-12.

11. Shaish A, Harari A, Hananshvili L, et al. (2006) 9-Cis $\beta$-carotene-rich powder of the alga Dunaliella bardawil increases plasma HDL-cholesterol in fibrate-treated patients. Atherosclerosis 189, 215-221.

12. Castelli WP (1996) Lipids, risk factors and ischaemic heart disease. Atherosclerosis 124, 1-9.

13. Wong KH, Sam SW, Cheung PCK, et al. (1999) Changes in lipid profiles of rats fed with seaweed-based diets. Nutr Res 19, 1519-1527.

14. Ross R (1999) Atherosclerosis - an inflammatory disease. $N$ Engl J Med 340, 115-126.

15. Canales A \& Sánchez-Muniz FJ (2003) Paraoxonase, something more than an enzyme? Med Clin (Barc) 121, 537-548.

16. Nus M, Sánchez-Muniz FJ \& Sánchez-Montero JM (2006) A new method for the determination of arylesterase activity in human serum using simulated body fluid. Atherosclerosis 188, $155-159$.

17. Nus M, Sánchez-Muniz FJ, Sinisterra Gago JV, et al. (2008) Determination of rat and mice arylesterase activity using serum mimetics. Enzyme Microb Technol 43, 252-256.

18. Nus M, Sánchez-Muniz FJ \& Sánchez-Montero JM (2007) Arilesterasa. Aspectos metodológicos y funcionales de un enzima clave en la enfermedad cardiovascular. Parte I (Arylesterase. Methodological and functional aspects of a key enzyme in cardiovascular disease. Part I). An $R$ Acad Nat Farm 74, 5-27.

19. Wright MO, Burden V, Lee J, et al. (1999) High dietary iron enhances oxidative stress in liver but does not increase aberrant crypt foci development in rats with low vitamin $\mathrm{E}$ status. Nutr Cancer 35, 143-152.

20. Terpstra AH, Woodward CJ \& Sanchez-Muniz FJ (1981) Improved techniques for the separation of serum lipoproteins by density gradient ultracentrifugation: visualization by prestaining and rapid separation of serum lipoproteins from small volumes of serum. Anal Biochem 111, 149-157.

21. Viejo J, García-Linares C, Bastida S, et al. (2003) Effect of olive oil-fried sardine consumption on liver lipid composition and fatty acid cholesterol esterification in hypercholesterolemic rats. Food Sci Technol Int 9, 329-338.22.

22. Sánchez-Muniz FJ, García-Linares MC, García-Arias MT, et al. (2002) Fat and protein from olive oil-fried sardines interact to normalize serum lipoproteins and reduce liver lipids in hypercholesterolemic rats. J Nutr 133, 2302-2308.

23. Beynen AC, Boogaard A, Van Laack HL, et al. (1984) Cholesterol metabolism in two strains of rats with high or low response of serum cholesterol to a cholesterol-rich diet. J Nutr 114, 1640-1651.

24. Jacques H (1990) Effects of dietary fish proteins on plasma cholesterol and lipoproteins in animal models and in humans. In Dietary Proteins, Cholesterol Metabolism and Atherosclerosis, pp. 59-70 [M Sugano and AC Beynen, editors]. Basle: Karger Basel.

25. Chiang MT, Chen YC \& Huang AL (1998) Plasma lipoprotein cholesterol levels in rats fed a diet enriched in cholesterol and cholic acid. Int J Vitam Nutr Res 68, 328-334.

26. Sánchez-Muniz FJ, Higón E, Cava F, et al. (1992) Prevention of dietary hypercholesterolemia in rats using sunflower oil-fried sardines. Effects on cholesterol and serum enzymes. J Agric Food Chem 40, 2226-2231.

27. Sánchez-Muniz FJ, Viejo JM \& Medina R (1992) Deep frying of sardines in different culinary fats. Changes in the fatty acid composition of sardines and frying fats. J Agric Food Chem 40, 2252-2256.

28. Terpstra AH, Lapre JA, De Vrie HT, et al. (2000) Hypocholesterolemic effect of dietary psyllium in female rats. Ann Nutr Metab 44, 223-228.

29. Sanchez-Muniz FJ \& Bastida S (2008) Do not use the Friedewald formula to calculate LDL-cholesterol in hypercholesterolaemic rats. Eur J Lipid Sci Technol 110, 295-301.

30. García-Linares MC, Bastida S, García-Arias MT, et al. (2003) Effect of olive oil-fried sardine consumption on liver lipid composition and fatty acid cholesterol esterification in hypercholesterolemic rats. Food Sci Tech Int 9, 329-338.

31. Vázquez J \& Sánchez-Muniz FJ (1994) Proteína de pescado y metabolismo de colesterol (Fish protein and cholesterol metabolism). Rev Esp Cienc Tecnol Aliment 34, 589-608.

32. Fuhrman B, Volkova N \& Aviram M (2005) Paraoxonase 1 (PON1) is present in postprandial chylomicrons. Atherosclerosis 180, 55-61.

33. Aviram M (2004) Introduction to the serial review on paraoxonases, oxidative stress, and cardiovascular diseases. Free Radic Biol Med 37, 1301-1303.

34. Rock W, Rosenblat M, Miller-Lotan R, et al. (2008) Consumption of wonderful variety pomegranate juice and extract by diabetic patients increases paraoxonase 1 association with high-density lipoprotein and stimulates its catalytic activities. I Agric Food Chem 56, 8704-8713.

35. Garrido-Polonio C, García-Linares MC, García-Arias MT, et al. (2004) Thermally oxidised sunflower-seed oil increases liver and serum peroxidation and modifies lipoprotein composition in rats. BrJ Nutr 92, 257-265.

36. Sigurdsson G, Nicoli A \& Lewis B (1975) Conversion of very low density lipoprotein to low density lipoprotein. A metabolic study of apolipoprotein B kinetics in human subjects. J Clin Invest 56, 1481-1490.

37. Sánchez-Muniz FJ, García-Linares MC, García-Arias MT, et al. (2003) Fat and protein from olive oil-fried sardines interact to normalize serum lipoproteins and reduce liver lipids in hypercholesterolaemic rats. J Nutr 133, 2302-2308.

38. Gueux E, Mazur A, Rayssiguier Y, et al. (1996) Lipid fluidity of triacylglycerol-rich lipoproteins isolated from copperdeficient rats. Br J Nutr 75, 767-773. 
39. Bocanegra A, Nieto A, Blas B, et al. (2003) Diets containing a high percentage of Nori or Konbu algae are well-accepted and efficiently utilised by growing rats but induce different degrees of histological changes in the liver and bowel. Food Chem Toxicol 41, 1473-1480.

40. Krauss RM, Eckel HR, Howard B, et al. (2000) AHA dietary guidelines. Revision 2000: a statement for healthcare professionals from the Nutrition Committee of the American Heart Association. Circulation 102, 2284-2299.

41. Fukushima M, Ohhashi T, Ohno S, et al. (2001) Effects of diets enriched in $n-6$ or $n$-3 fatty acids on cholesterol metabolism in older rats chronically fed a cholesterol-enriched diet. Lipids 36, 261-266.

42. Reilly MP, Pratico D, Delanty N, et al. (1998) Increased formation of distinct F2 isoprostanes in hypercholesterolemia. Circulation 98, 2785-2787.

43. Aviram M, Rosenblat M, Bisgaier CL, et al. (1998) Paraoxonase inhibits high density lipoproteins (HDL) oxidation and preserves its functions, a possible peroxidative role for paraoxonase. J Clin Invest 101, 1581-1590.

44. Murata M, Sano Y, Ishihara K, et al. (2001) Dietary fish oil and Undaria pinnatifida (Wakame) synergistically decrease rat serum and liver triacylglycerol. $J$ Nutr 132, 742-747.

45. Jimenez-Escrig A \& Sanchez-Muniz FJ (2000) Dietary fibre from edible seaweeds: chemical structure, physicochemical properties and effects on cholesterol metabolism. Nutr Res 20, 585-598.

46. Sigurdsson G, Nicoli A \& Lewis B (1975) Conversion of very low density lipoprotein to low density lipoprotein. A metabolic study of apolipoprotein B kinetics in human subjects. J Clin Invest 56, 1481-1490.

47. Havel RJ (1984) The formation of LDL: mechanisms and regulation. J Lipid Res 25, 1570-1576.

48. Acton S, Rigotti A, Landschultz KT, et al. (1996) Identification of scavenger receptor SR-BI as a high density lipoprotein receptor. Science 271, 518-520.

49. Mardones P, Quinones V, Amigo L, et al. (2001) Hepatic cholesterol and bile acid metabolism and intestinal cholesterol absorption in scavenger receptor class B type I-deficient mice. J Lipid Res 42, 170-180.

50. Zhou H, Li Z, Silver LD, et al. (2006) Cholesteryl ester transfer protein (CETP) expression enhances HDL cholesteryl ester liver delivery, which is independent of scavenger receptor BI, LDL receptor related protein and possibly LDL receptor. Biochim Biophys Acta 1761, 1482-1488.

51. Braun A, Trigatti BL, Post MJ, et al. (2000) Loss of SR-BI expression leads to the early onset of occlusive atherosclerotic coronary artery disease, spontaneous myocardial infarctions, severe cardiac dysfunction, and premature death in apoE-deficient mice. Circ Res 90, 270-276. 